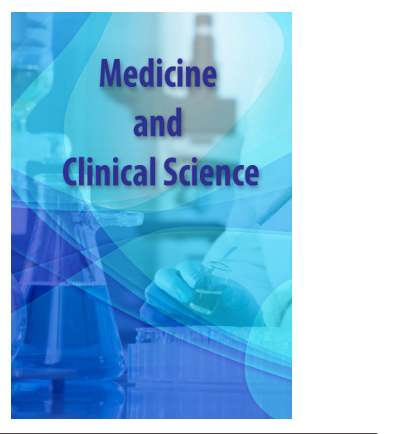

Correspondence

Natalia Rakislova.

ISGlobal, Hospital Clinic of Barcelona, Universitat de Barcelona, Villarroel, 170, Barcelona, 08036, Spain

Tel.: +34 932271851

E-mail: RAKISLOVA@clinic.cat

- Received Date: 07 June 2020

- Accepted Date: 15 June 2020

- Publication Date: 24 June 2020

Keywords

Autopsy; Minimally Invasive Autopsy; coronavirus, COVID-19; post-mortem in COVID-19 cases; SARS-COV-2; autopsy biosafety

Copyright

(C) 2020 Science Excel. This is an openaccess article distributed under the terms of the Creative Commons Attribution 4.0 International license.

\title{
Minimally Invasive Autopsy: a more feasible and safer alternative to conventional autopsy in the COVID-19 pandemic era?
}

\author{
Natalia Rakislova ${ }^{1,2^{*}}$, Mamudo R Ismail ${ }^{3}$, Antonio Martinez ${ }^{2}$, Carla Carrilho ${ }^{3}$, \\ Miguel J Martinez ${ }^{1,4}$, Quique Bassat ${ }^{1,5,6,7,8}$, Jaume Ordi ${ }^{1,2, \#}$, Clara Menéndez ${ }^{1,5,8, \#}$ \\ 'ISGlobal, Barcelona Institute for Global Health, Hospital Clínic-Universitat de Barcelona, Barcelona, Spain \\ ${ }^{2}$ Department of Pathology, Hospital Clinic, Universitat de Barcelona, Spain \\ ${ }^{3}$ Department of Pathology, Maputo Central Hospital, Maputo, Faculty of Medicine, Eduardo Mondlane University, Maputo, \\ Mozambique \\ ${ }^{4}$ Department of Microbiology, Hospital Clinic, Universitat de Barcelona, Spain \\ ${ }^{5}$ Centro de Investigação em Saúde de Manhiça, (CISM), Maputo, Mozambique \\ ${ }^{6}$ ICREA, Pg. Lluís Companys 23, 08010 Barcelona, Spain \\ ${ }^{7}$ Pediatric Infectious Diseases Unit, Pediatrics Department, Hospital Sant Joan de Déu (University of Barcelona), Barcelona, Spain \\ ${ }^{8}$ Consorcio de Investigación Biomédica en Red de Epidemiología y Salud Pública (CIBERESP), Madrid, Spain \\ \# These authors equally contributed to the study and share senior authorship
}

\begin{abstract}
Robust evidence on the pathogenesis and pathological findings of most diseases is based on autopsy examination. In view of the many knowledge gaps still hindering our current understanding of SARSCoV-2 infection, post-mortem studies in this life-threatening disease are urgently needed. However, due to logistic and especially biohazard challenges less than 50 post-mortem examinations have been conducted in patients dying from COVID-19; most of them adult males with comorbidities. A few years ago, our group developed and validated in all age-groups a standardised minimally invasive autopsy (MIA) protocol, which might be a safer and more feasible approach to investigate SARS-CoV-2-related deaths. This MIA method is highly accurate in exploring infection-related deaths and may represent a valid post-mortem approach in all settings during the COVID-19 pandemic, especially in those lacking adequate facilities to perform high-risk autopsies. Expansion in the use of MIA might contribute to eliminate the current knowledge gaps on the COVID-19 disease, especially in pediatric deaths and in cases with unusual clinical features.
\end{abstract}

\section{Introduction}

The new coronavirus disease, or severe acute respiratory syndrome coronavirus 2 (SARSCoV-2), emerged at the end of 2019 in the city of Wuhan, in the Chinese province of Hubei. On January 30, 2020, it was declared a public health emergency of international concern by the World Health Organization (WHO)[1]. In the following weeks, the disease was officially designated as Coronavirus Disease-2019 (COVID-19) and officially declared a pandemic by the WHO [2]. Since then, it has become clear that SARS-CoV-2 infection is a highly contagious and harmful infectious disease. Merely 4 months after the first cases were detected, it has spread to more than 200 countries around the world, causing over 3 million confirmed cases and over 200,000 deaths [3]. While SARS-CoV-2 steadily continues to spread, all the countries affected are making enormous efforts to effectively control the pandemic, which is heavily impacting health systems and economies.

Most patients with SARS-CoV-2 infection have mild clinical symptoms. However, a small proportion develops severe respiratory disease with a high mortality rate [4]. Older individuals and patients with chronic diseases are at higher risk of developing severe COVID-19 disease and dying. Severe and life-threatening disease may, however, also occur in younger adults with no pre-existing conditions. From the clinical experience acquired during the few months of the pandemic, it has been recognized that SARSCoV-2 mostly affects the lungs, frequently showing bilateral and multifocal involvement on CT scans [5-7]. It is also speculated that the cardiovascular system can be severely damaged in some cases, leading to severe myocarditis [8,9]. Additionally, some patients show clinical signs of encephalitis [10] and meningitis [11]. In the last days, reports of Kawasaki-like and/or toxic shock syndrome have also been reported as a possible clinical presentation of COVID-19 in children, but very little is yet known of this unusual new presentation [12]. Altogether, the uncertainties regarding what happens at the pathophysiological level call for the need for robust post-mortem examinations. Unfortunately, no autopsy has been conducted in any of these cases with unusual clinical features to confirm clinical suspicion [8-11]. Indeed, there are still important knowledge gaps on how COVID-19 

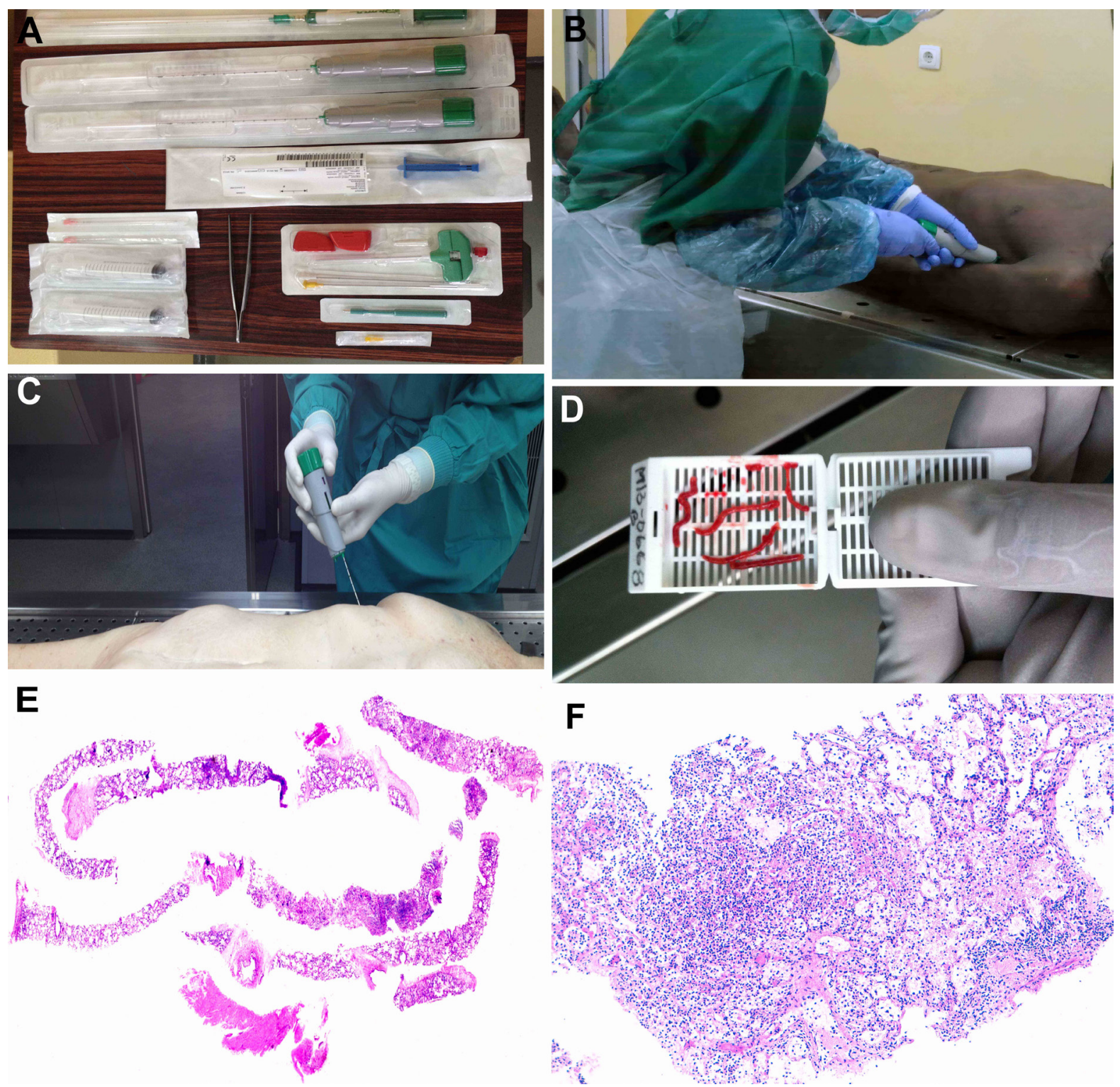

Figure 1. Minimally Invasive Autopsy method A, Tools for sample collection in adults: automatic needles for punctures of solid organs (upper part of the image); fine needles and syringes for blood and cerebrospinal fluid collection (lower left corner) and bone marrow biopsy needle (lower right corner). B, and C, MIA specialist using automatic needle aiming to collect heart and lung samples, respectively. D, Cores of lung tissue obtained during MIA. E, Representative image of histologically processed cores of lung tissue at low power view (x10). F, Higher power magnification (x160) of lung tissue shows clear signs of severe acute pneumonia.

disease affects human organs and systems and the pathological basis of the severe complications [13]. At present, throughout the world researchers from different fields are making significant progress in characterising the disease and understanding ways to control this infection. However, most studies focus on the development of vaccines and molecular diagnostic methods. In contrast, postmortem studies aiming to explore the pathological lesions in fatal COVID-19 disease, which may provide fundamental insights into the pathogenesis of the disease [13], are still scarce. Here in we review the available autopsy evidence on COVID-19 disease and discuss why minimally invasive approach might be relevant to expand the use of post-mortem studies, providing valuable knowledge for treatment, diagnosis and prevention.

\section{Post-mortem findings in COVID-19 disease: what do we know so far?}

Up to date, about 100 post-mortem procedures in COVID-19 cases have been documented in the literature [6,7,14-23], with the biggest series reporting 21 cases [21]. Twenty-nine post-mortem procedures (20\% of all autopsies) were performed using minimally invasive (needle-based) approach [17-20,24,25]. The majority of the deceased patients were adult males with comorbidities [6,7,17-23]; mostly with cardiovascular conditions [6,7,15,17-21]. Lungs were severely damaged in all cases $[17-20,24,25]$. The most frequent finding was diffuse alveolar damage, frequently associated with interstitial lymphocytic infiltrate of variable degrees (viral pneumonia) $[6,7,17$ 22]. Several studies also reported thrombotic lesions, predominantly 
in the lungs or the kidneys $[6,18,21]$, as well as pulmonary embolisms $[6,21]$. Myocarditis was an exceptional finding $[6,18]$. None of the studies reported encephalitis. Interestingly, one study reported high prevalence of blood group A, and of senile cardiac amyloidosis [6]. Only one study reported the presence of viral inclusions in the respiratory epithelium [15].

\section{Role and feasibility of conventional autopsy in exploring} fatal COVID-19 disease

It is well-known that classic autopsy with detailed examination of internal organs followed by tissue sampling for histological evaluation (and, if required, microbiological and molecular analyses) is the most complete method to study how diseases (including infectious diseases) affect different organs and systems [26,27]. However, as described above, there is a clear lack of international efforts focused on performing autopsies in suspected or confirmed COVID-19 cases and less than 50 post-mortem examinations have been documented so far worldwide [6,7,18-21]. The main reasons for this scarcity of pathologic studies include the re-prioritization of essential health care measures to the living and severely sick, the huge workload of health professionals, and the non-negligible logistical challenges imposed by a highly contagious infection to guarantee biosafety during the procedure. In addition, adequate infrastructures, including certified biosafety level-3 facilities, and special personal protective equipment (PPE) have been recommended to perform autopsies in these cases $[28,29]$. These requirements are difficult to meet during the current pandemic, as even many third level health facilities are experiencing significant economic and logistic challenges. Indeed, there is a lack of PPE even for physicians attending COVID-19-infected patients. Additionally, some governments and national pathology societies strongly advise against autopsy in COVID-19 cases. These reasons might explain, in part, the fact that many hospitals in affected countries have preferred not to perform autopsies during the current pandemic. Unfortunately, as has been shown in the history of medicine, a lack of post-mortem studies may hinder or delay scientific progress in understanding the pathogenesis of emerging diseases [13] and lead to distortions of data on the cause of death [30].

\section{What is a minimally invasive autopsy?}

The minimally invasive autopsy (MIA), also known as minimally invasive tissue sampling (MITS), was designed by our group in 2013, as an alternative to conventional autopsy for use in low-income settings, where the lack of infrastructures and human resources, together with the poor acceptability of "invasive" post-mortem procedures, prevents performing complete autopsies of sufficient quality [31]. The MIA is a standardised, needle-based, post-mortem examination that is performed without opening the body and without using any sophisticated image-based techniques to guide the sampling [32]. Figure 1 illustrates MIA sampling procedure. The procedure is simple, requires only a basic autopsy room and can be successfully performed, not only by fully trained pathologists, but also by other physicians or less qualified technicians or nurses after receiving basic training [33]. Briefly, a MIA consists of inserting fine needles into the body (Figure $1 \mathrm{~B}$ and $1 \mathrm{C}$ ), aimed at collecting

\begin{tabular}{|c|c|c|c|c|c|c|c|c|}
\hline References & Country & $\begin{array}{l}\text { No of } \\
\text { cases }\end{array}$ & $\begin{array}{c}\text { Mean age } \\
\text { years (range) }\end{array}$ & $\begin{array}{l}\text { Male:female } \\
\text { ratio }\end{array}$ & $\begin{array}{l}\text { Ultrasound } \\
\text { Guidance }\end{array}$ & $\begin{array}{c}\text { Sampled } \\
\text { organs }\end{array}$ & $\begin{array}{l}\text { Lung lesions (n; } \\
\%)\end{array}$ & $\begin{array}{l}\text { Other interesting pathologi- } \\
\text { cal findings }(\mathrm{n} ; \%)\end{array}$ \\
\hline Zhang et al [20] & China & 1 & $72(\mathrm{~N} / \mathrm{A})$ & $1: 00$ & No & Lungs & DAD $(1 ; 100 \%)$ & - \\
\hline $\mathrm{Xu}$ et al [17] & China & 1 & 50 (N/A) & 1:00 & No & $\begin{array}{l}\text { Lungs, heart, } \\
\text { liver }\end{array}$ & DAD $(1 ; 100 \%)$ & - \\
\hline Tian et al [19] & China & 4 & $73(59-81)$ & 3:01 & No* & $\begin{array}{l}\text { Lung, liver, } \\
\text { Heart ( } 2 \text { cases })\end{array}$ & $\begin{array}{l}\text { DAD }(4 ; 100 \%) \\
\text { Pneumonia }(1 ; \\
25 \%)\end{array}$ & - \\
\hline Yao et al [18] & China & 3 & $70(63-79)$ & 2:01 & No & $\begin{array}{l}\text { Lung, heart, } \\
\text { liver, kidney, } \\
\text { spleen, bone } \\
\text { marrow, } \\
\text { pancreas, } \\
\text { stomach, } \\
\text { intestine, } \\
\text { thyroid and } \\
\text { skin }\end{array}$ & $\begin{array}{l}\text { DAD (N/S) } \\
\text { Pneumonia (N/S) }\end{array}$ & $\begin{array}{l}\text { Mild myocarditis }(\mathrm{N} / \mathrm{S}) \\
\text { Hypocellular bone marrow } \\
\text { and spleen }(\mathrm{N} / \mathrm{S}) \\
\text { Thrombi in kidneys }(\mathrm{N} / \mathrm{S})\end{array}$ \\
\hline Wu et al [24] & China & 10 & $70(39-87)$ & $7: 03$ & Yes & Lungs & $\begin{array}{l}\text { DAD }(9 ; 90 \%) \\
\text { Bacterial co- } \\
\text { infection }(1 ; 10 \%) \\
\text { Fungal co- } \\
\text { infection }(1 ; 10 \%)\end{array}$ & $\begin{array}{l}\text { Capillary hyaline thrombus } \\
\text { and intravascular mixed } \\
\text { thrombus in lung tissue (N/S) }\end{array}$ \\
\hline $\begin{array}{l}\text { Duarte-Neto et } \\
\text { al [15] }\end{array}$ & Brazil & 10 & $69(33-83)$ & $5: 05$ & Yes & $\begin{array}{l}\text { Lungs, liver, } \\
\text { heart, kidneys, } \\
\text { spleen, brain, } \\
\text { skin, skeletal } \\
\text { muscle and } \\
\text { testis }\end{array}$ & $\begin{array}{l}\text { DAD }(10 ; 100 \%) \\
\text { Pneumonia }(6 ; \\
60 \%)\end{array}$ & $\begin{array}{l}\text { Myositis }(2 ; 20 \%) \\
\text { Orrchitis }(2 ; 20 \%) \\
\text { Mild myocarditis }(2 ; 20 \%)) \\
\text { Fibrinous thrombi in alveolar } \\
\text { arterioles }(8 ; 80 \%) \\
\text { Intense pleomorphic } \\
\text { cytopathic effects on the } \\
\text { respiratory epithelium }(6 ; \\
60 \%) \\
\text { High density of alveolar } \\
\text { megakaryocytes }(10 ; 100 \%)\end{array}$ \\
\hline
\end{tabular}

DAD: diffuse alveolar damage; DVT: deep venous thrombosis; N/A not applicable; N/S: not specified; PE: pulmonary embolism

Table 1. Summary of minimally invasive autopsy (MIA) findings in COVID-19 positive deceased patients 
fluids (blood, cerebrospinal fluid, effusions etc.) and cores of tissue (Figure $1 \mathrm{D}$ and $1 \mathrm{E}$ ) from key, highly informative organs such as the lungs, liver, brain and heart $[32,33]$. The success of this technique in obtaining samples of these organs is close to $100 \%$ [32]. These samples are analysed through histopathological and microbiological methods, and provide evidence on the pathological lesions (Figure 1 F) and the infectious agents responsible for the fatal outcome [34]. In addition, not only the final cause of death, but also the chain of events leading to death can be successfully determined in most cases $[33,35]$.

\section{Potential role of the MIA in exploring fatal COVID-19 disease}

We have validated our standardised MIA approach against complete autopsy in different age groups, including adult, paediatric and maternal deaths [35-39]. The technique has shown adequate concordance with the complete autopsy in all age groups, and importantly, a particularly high performance for infectious diseases [35,37-39]. Taking into account that the lungs may show severe multifocal and bilateral damage in individuals with COVID-19 infection [5], and that its radiological and pathogenic evolution is still poorly known [40], MIA may provide relevant information to understand these lesions. In addition, it is difficult to determine the chain of events leading to death in some patients and to ascertain how many patients die due to SARS-CoV-2 or with SARS-CoV-2, for example by secondary infections complicating the viral infection [9] or other conditions aggravated by the viral disease.

To the best of our knowledge, MIA approach has not been implemented in cases of highly transmissible infectious diseases with high mortality rates, such as hemorrhagic fevers (e.g., Ebola virus disease), with the exception of a few cases of a MIA-like procedure utilized in the investigation of Nipah Virus infections in Bangladesh [41] and yellow fever in Brazil [42].

Similar minimally invasive approaches have been used in a few COVID-19-related deaths in China during the current pandemic. Table 1 summarizes the main pathological findings from the 9 published post-mortem studies that employed MIA approach. (Table 1). Overall, 6 studies reported 29 MIA procedures. However, the sampling was restricted to the lungs [20,24], including also sampling of liver and/or heart in some cases $[17,19]$. Only a two studies, conducted in China and Brazil, have used an almost identical approach to our MIA protocol, with sampling of a wide range of organs $[15,18]$. We strongly believe that a protocolized approach, involving the systematic collection of tissues from key organs and bodily fluids is necessary not only to confirm the impact of the infection in each organ, but also to better determine the chain of the events leading to death.

\section{Biosafety of MIA during the COVID-19 pandemic}

There is no solid evidence on how safe the MIA procedure is in COVID-19-infected individuals. Among the four studies that have recently performed MIA in COVID-19 cases [15], only one [19] indicated the room in which the procedure was carried out (negative air isolation ward). Our standardised MIA method has not been extensively used in the context of highly contagious emerging infectious diseases, such as COVID-19 infection, with the few abovementioned exceptions, mainly conducted in China $[18,20]$. Nevertheless, up to now, we have safely performed over 600 MIA procedures, including a high number of cases with HIV and/or active tuberculosis. The autopsy room we used was standard (with no negative air pressure). In all of these procedures, basic universal precautions have been followed [43], including conventional autopsy PPE [hair cap, surgical mask, gown, apron, gloves, googles and boots] (Figure $1 \mathrm{~B}$ ), and none of the technicians and pathologists performing the procedures have suffered any incident or infection. It is clear that the transmission routes of COVID-19 infection might be different from HIV (blood-borne route), being more similar to tuberculosis (airborne and droplet route) [44]. However, it is important to take into consideration that in a MIA procedure the body is not opened, and consequently, the generation of infective aerosols from organs and fluids is extremely unlikely. However, the procedure should not be considered as exempt of risks. In fact, any routine conventional autopsy can actually turn out to be a previously unsuspected highly infectious disease.

From our point of view, MIA can be performed following reinforced universal PPE measures. Appropriate PPE must be available for each person involved in the procedure; a mask (N95, FFP2/3 masks are highly recommendable), scrub suit, long sleeved fluid-resistant gown, gloves, cap to protect hair, eye protection (goggles or face shield), and boots $[29,45]$. Full body suits that include a powered air-purifying respirator providing $100 \%$ protection can be used but are not absolutely necessary. Without doubt, autopsy room with negative air pressure is highly recommendable for any post-mortem procedure dealing with COVID-19-related deaths [29]. However, since aerosol generation is unlikely during MIA, in our opinion, any adequately ventilated standard autopsy room is suitable for performing MIA in suspected or confirmed SARS-CoV-2 cases [45]. A critical biosafety rule for the MIA procedure would be the application of thorough disinfection of surfaces and tools, during and after the procedure $[45,46]$. Additionally, the number of personnel performing MIA should be reduced to a minimum, and all should have sufficient training [45].

\section{Conclusions}

Post-mortem examinations to determine the chain of events leading to death and the final causes of death are key to characterising and understanding new diseases, such as SARS-CoV-2 infection. Indeed, even in many well-known "old diseases" (e.g. chronic pulmonary disease), there are significant uncertainties about the final events leading to death that have not been completely elucidated. There are still some uncertainties about COVID-19 pathogenesis; especially in clinically challenging paediatric cases. Given the biological risk and challenges of performing conventional autopsies, MIA may be considered as a simpler and more adequate alternative in these cases. Despite the limited experience of performing MIA in COVID19-related deaths, we consider that a basic, well-ventilated autopsy room, the use of reinforced PPE together with thorough disinfection measures should suffice to perform this procedure in suspected or confirmed COVID-19 cases. Absence of certified biosafety level-3 facilities should not be an obstacle to perform MIA.

\section{References}

1. World Health Organization. Novel Coronavirus(2019-nCoV) Situation Report - 11 2020. https://www.who.int/blueprint/ priority- (accessed April 28, 2020).

2. Wu YC, Chen CS, Chan YJ. The outbreak of COVID-19: An overview. J Chinese Med Assoc 2020;83:217-20.

3. Situation update worldwide, as of 26 April 2020 n.d. https:// www.ecdc.europa.eu/en/geographical-distribution-2019-ncovcases (accessed April 26, 2020).

4. Wu Z, McGoogan JM. Characteristics of and Important Lessons from the Coronavirus Disease 2019 (COVID-19) Outbreak in China: Summary of a Report of 72314 Cases from the Chinese Center for Disease Control and Prevention. JAMA - J Am Med Assoc 2020;323:1239-42.

5. Ding X, Xu J, Zhou J, Long Q. Chest CT findings of COVID-19 pneumonia by duration of symptoms. Eur J Radiol 2020;127:109009.

6. Wichmann D, Sperhake J-P, Lütgehetmann M, Steurer S, Edler C, Heinemann A, et al. Autopsy Findings and Venous Thromboembolism in Patients With COVID-19: A Prospective Cohort Study. Ann Intern Med. 2020;M20-2003.

7. Barton LM, Duval EJ, Stroberg E, Ghosh S, Mukhopadhyay S. COVID-19 Autopsies, Oklahoma, USA. Am J Clin Pathol. 2020; 153(6): 725-733.

8. Irabien-Ortiz Á, Carreras-Mora J, Sionis A, Pàmies J, Montiel J, Tauron M. Fulminant myocarditis due to COVID-19. Rev Esp Cardiol (Engl Ed). 2020;73(6):503-504.

9. Zeng J-H, Liu Y-X, Yuan J, Wang F-X, Wu W-B, Li J-X, et al. First case of COVID-19 complicated with fulminant myocarditis: a 
case report and insights. Infection 2020:1-5.

10. Ye M, Ren Y, Lv T. Encephalitis as a clinical manifestation of COVID-19. Brain Behav Immun. 2020;S0889-1591(20)30465-7.

11. Moriguchi T, Harii N, Goto J, Harada D, Sugawara H, Takamino J, et al. A first Case of Meningitis/Encephalitis associated with SARS-Coronavirus-2. Int J Infect Dis 2020;94:55-8.

12. Jones VG, Mills M, Suarez D, Hogan CA, Yeh D, Bradley Segal J, et al. COVID-19 and Kawasaki Disease: Novel Virus and Novel Case. Hosp Pediatr. 2020;10(6):537-540.

13. Pomara C, Volti GL, Cappello F. COVID-19 Deaths: Are We Sure It Is Pneumonia? Please, Autopsy, Autopsy, Autopsy! J Clin Med. 2020;9:1259.

14. Konopka KE, Nguyen T, Jentzen JM, Rayes O, Schmidt CJ, Wilson AM, et al. Diffuse Alveolar Damage (DAD) from Coronavirus Disease 2019 Infection is Morphologically Indistinguishable from Other Causes of DAD. Histopathology 2020:his.14180.

15. Nunes Duarte-Neto A, de Almeida Monteiro RA, da Silva LFF, Malheiros DMAC, de Oliveira EP, Theodoro Filho J, et al. Pulmonary and systemic involvement of COVID-19 assessed by ultrasound-guided minimally invasive autopsy. Histopathology 2020.

16. Quan GL, Gao YG, Yang AS. Postmortem Examination in Two Cases of Death Related to 2019-nCoV Infection and the Experience of On-site Protection. Fa Yi Xue Za Zhi 2020;36:17680.

17. Xu Z, Shi L, Wang Y, Zhang J, Huang L, Zhang C, et al. Pathological findings of COVID-19 associated with acute respiratory distress syndrome. Lancet Respir Med 2020;8:420-2.

18. Yao XH, Li TY, He ZC, Ping YF, Liu HW, Yu SC, et al. [A pathological report of three COVID-19 cases by minimally invasive autopsies]. Zhonghua Bing Li Xue Za Zhi = Chinese J Pathol 2020;49:E009.

19. Tian S, Xiong Y, Liu H, Niu L, Guo J, Liao M, et al. Pathological study of the 2019 novel coronavirus disease (COVID-19) through postmortem core biopsies. Mod Pathol 2020:1-8.

20. Zhang $\mathrm{H}$, Zhou $\mathrm{P}$, Wei $\mathrm{Y}$, Yue $\mathrm{H}$, Wang $\mathrm{Y}, \mathrm{Hu} \mathrm{M}$, et al. Histopathologic Changes and SARS-CoV-2 Immunostaining in the Lung of a Patient With COVID-19. Ann Intern Med 2020.

21. Menter T, Haslbauer JD, Nienhold R, Savic S, Hopfer $H$, Deigendesch N, et al. Post-mortem examination of COVID19 patients reveals diffuse alveolar damage with severe capillary congestion and variegated findings of lungs and other organs suggesting vascular dysfunction. Histopathology 2020:his.14134.

22. Lacy JM, Brooks EG, Akers J, Armstrong D, Decker L, Gonzalez $\mathrm{A}$, et al. COVID-19: Postmortem diagnostic and biosafety considerations. Am J Forensic Med Pathol 2020:1.

23. Konopka KE, Wilson A, Myers JL. Postmortem Lung Findings in an Asthmatic with Coronavirus Disease 2019 (COVID-19). Chest 2020.

24. Wu JH, Li X, Huang B, Su H, Li Y, Luo DJ, et al. [Pathological changes of fatal coronavirus disease 2019 (COVID-19) in the lungs: report of 10 cases by postmortem needle autopsy]. Zhonghua Bing Li Xue Za Zhi = Chinese J Pathol 2020;49:568575 .

25. Monteiro RAA, Duarte-Neto AN, da Silva LFF, de Oliveira EP, Filho JT, dos Santos GAB, et al. Ultrasound-guided Minimally Invasive Autopsies: A Protocol for the Study of Pulmonary and Systemic Involvement of COVID-19. Clinics 2020;75.

26. Shieh WJ, Blau DM, Denison AM, DeLeon-Carnes M, Adem P, Bhatnagar J, et al. 2009 Pandemic influenza A (H1N1): Pathology and pathogenesis of 100 fatal cases in the United States. Am J Pathol 2010;177:166-75.

27. Costache M, Lazaroiu AM, Contolenco A, Costache D, George $\mathrm{S}$, Sajin M, et al. Clinical or postmortem? The importance of the autopsy; a retrospective study. Maedica (Buchar) 2014;9:261-5.

28. Mao D, Zhou N, Zheng D, Yue J, Zhao Q, Luo B, et al. Guide to forensic pathology practice for death cases related to coronavirus disease 2019 (COVID-19) (Trial draft). Forensic Sci
Res 2020:1-7.

29. Hanley B, Lucas SB, Youd E, Swift B, Osborn M. Autopsy in suspected COVID-19 cases. J Clin Pathol 2020:jclinpath-2020-206522.

30. Bassat Q, Castillo P, Alonso PL, Ordi J, Menéndez C. Resuscitating the Dying Autopsy. PLoS Med 2016;13.

31. Ekanem V, Vhriterhire C. Relevance of clinical auto psy in medical practice in Sub-Saharan Africa. Sahel Med J 2015;18:49.

32. Castillo P, Ussene E, Ismail MR, Jordao D, Lovane L, Carrilho C, et al. Pathological Methods Applied to the Investigation of Causes of Death in Developing Countries: Minimally Invasive Autopsy Approach. PLoS One 2015;10:e0132057.

33. Rakislova N, Fernandes F, Lovane L, Jamisse L, Castillo P, Sanz A, et al. Standardization of Minimally Invasive Tissue Sampling Specimen Collection and Pathology Training for the Child Health and Mortality Prevention Surveillance Network. Clin Infect Dis 2019;69:S302-10.

34. Martinez MJ, Massora S, Mandomando I, Ussene E, Jordao D. Infectious cause of death determination using minimally invasive autopsies in developing countries. Diagn Microbiol Infect Dis 2016;84:80-6.

35. Castillo P, Martínez MJ, Ussene E, Jordao D, Lovane L, Ismail MR, et al. Validity of a Minimally Invasive Autopsy for Cause of Death Determination in Adults in Mozambique: An Observational Study. PLOS Med 2016;13:e1002171.

36. Menendez C, Castillo P, Martínez MJ, Jordao D, Lovane L, Ismail MR, et al. Validity of a minimally invasive autopsy for cause of death determination in stillborn babies and neonates in Mozambique: An observational study. PLOS Med 2017;14:e1002318.

37. Bassat Q, Castillo P, Martínez MJ, Jordao D, Lovane L, Hurtado JC, et al. Validity of a minimally invasive autopsy tool for cause of death determination in pediatric deaths in Mozambique: An observational study. PLOS Med 2017;14:e1002317.

38. Castillo P, Hurtado JC, Martínez MJ, Jordao D, Lovane L, Ismail $\mathrm{MR}$, et al. Validity of a minimally invasive autopsy for cause of death determination in maternal deaths in Mozambique: An observational study. PLoS Med 2017;14:e1002431.

39. Palhares AEM, Ferreira L, Freire M, Castillo P, Martinez MJ, Hurtado JC, et al. Performance of the Minimally Invasive Autopsy tool for Cause of Death Determination in Adults Deaths from the Brazilian Amazon: An Observational Study. Virchows Arch 2019;475:649-58.

40. Lee EYP, Ng MY, Khong PL. COVID-19 pneumonia: what has CT taught us? Lancet Infect Dis 2020;20:384-5.

41. Gurley ES, Parveen S, Islam MS, Hossain MJ, Nahar N, Homaira $\mathrm{N}$, et al. Family and community concerns about post-mortem needle biopsies in a Muslim society. BMC Med Ethics 2011;12.

42. Duarte-Neto AN, Monteiro RA de A, Johnsson J, Cunha M dos P, Pour SZ, Saraiva AC, et al. Ultrasound-guided minimally invasive autopsy as a tool for rapid post-mortem diagnosis in the 2018 Sao Paulo yellow fever epidemic: Correlation with conventional autopsy. PLoS Negl Trop Dis 2019;13.

43. Hardin NJ. Infection control at autopsy: a guide for pathologists and autopsy personnel. Curr Diagnostic Pathol 2000;6:75-83.

44. World Health Organization. Modes of transmission of virus causing COVID-19: implications for IPC precaution recommendations 2020. https://www.who.int/news-room/ commentaries/detail/modes-of-transmission-of-virus-causingcovid-19-implications-for-ipc-precaution-recommendations

45. World Health Organization. Global surveillance for COVID-19 caused by human infection with COVID-19 virus: interim guidance, 20 April 2020. https://www.who.int/publications/i/ item/global-surveillance-for-covid-19-caused-by-humaninfection-with-covid-19-virus-interim-guidance

46. European Centre for Disease Control. Infection prevention and control for COVID-19 in healthcare settings - third update 13 May 2020. https://www.ecdc.europa.eu/en/publications-data/ infection-prevention-and-control-and-preparedness-covid-19healthcare-settings 